\title{
Iodine-Catalyzed Synthesis of Spiroorthcarbonates under Neutral Conditions
}

\author{
Mohammad Rahimizadeh, ${ }^{\times}$Mehdi Bakavoli, Ali Shiri, and Hossein Eshghi \\ Deparment of Chemistry, School of Sciences, Ferdonsi Lniversity of Mashhad, 91775-1436 Mashhad, Iran \\ "E-mail: rahimizhia vahoo.com \\ Received January 31, 2009, Accepted Hav 28, 2009
}

Key Words: Spiroorthocarbonate. Symmetrical. Unsymmetrical. Iodine. Catalỵst

Spiroorthocarbonates ( $\mathrm{SOCs}$ ) are one of the most important categories of monomers which polymerize without any shrinkage in volume. 'They are specially useful in the synthesis of materials such as precision materials. adhesives. and dental composites. $^{1-3}$

There are few methods for the synthesis of SOCs. Sakai et. al. reported a novel synthesis of SOCs from the reaction of organotin compounds with carbon disulfide. ${ }^{4.5}$ This method is not recommended. Since it involves many steps and lighly toxic unstable organotin compounds. Endo and Okawara also reported another synthetic method by treatment of tetraalky'orthocarbonate with various diols in the presence of $\mathrm{TsOH}$ as an acidic catalyst." The main disadvantage of this method comes from inevitable formation of symmetrical SOCs during the preparation of unsymmetrical analogs. Synthesis of SOCs is also achieved by using highly toxic thiophosgene which is not advised. The one pot treatment of dichlorodiphenosymethane and various diols is useful only for the synthesis of symmetrical SOCs. ${ }^{8}$ Endo used dichlorodiphenoxymethane in the presence of $p$-toluenesulfonic acid monohydrate for the preparation of asymmetric SOCs. ${ }^{9}$ The long reaction times and relatively low yields are the disadvantages of this method. Therefore: an alternative method that can overcome these drawbacks and can be applied to the synthesis of symmetrical and unsymmetrical SOCs is desirable.

Recently, molecular iodine has been the focus of attention in organic transformations as a mild. readily available and neutral Lewis acid. ${ }^{\text {ld }}$ In continuation of our previous research on spiroorthocarbonates, ${ }^{11.1 ?}$ in this paper. we wish to report on the use of this cataly'st for the synthesis of symmetrical and unsymmetrical SOCs from 2.2-diphenoxy-1.3-dioxane and 1.3-diol under neutral conditions. 2.2-Diphenoxy-1.3-dioxanes (1a-b) used in this work were prepared according to literature."

The reaction of 2.2-diphenoxy-1.3-dioxane (1a) with 1.3propanediol as a model reaction was performed in different aprotic solvents in the presence of $\mathrm{I}$. On the basis of the reaction times and yields. $\mathrm{CH}_{2} \mathrm{Cl}_{2}$ was selected as a most suitable solvent for the synthesis of SOCs.

Table 1. Optimization of molar ratio of the catalyst

\begin{tabular}{cccc}
\hline Entry & Catalyst $(\% \mathrm{~mol})$ & Reaction Time $(\mathrm{min})$ & Yield $(\%)$ \\
\hline 1 & 0.25 & 80 & 78 \\
2 & 0.5 & 30 & 95 \\
3 & 1 & 30 & 97 \\
4 & 2 & 30 & 97 \\
\hline
\end{tabular}

On the other hand. in order to get an insight into the optimum molar ratio of the catalyst. the model experiment was studied in four different molar ratios of the $\mathrm{I}_{\hat{2}}$, and the results clearly demonstrate that $0.5 \%$ molar ratio of $I_{2}$ related to 2.2 -diphenosy-1.3-dioxane is the optimal ratio. (Table 1)

2.2-Diphenoxy-1,3-dioxanes (1a-b) were reacted with various diols under neutral conditions in the presence of catalytic amount of molecular iodine $\left(0.5 \mathrm{~mol}^{\%}\right)$ in $\mathrm{CH}_{2} \mathrm{Cl}_{2}$ to yield the corresponding SOCs $(2 \mathbf{a}-\mathbf{j})$. (Scheme 1 )

The efficiency and validity of this method for the synthesis of SOCs $(2 a-j)$ can be deduced from the data in Table 2 . Moreover. the prolongation of the reaction has no effect on the product distribution unlike the previous published method which uses protic acid catalyst.

The proposed mechanism of the synthesis of SOCs catalyzed by molecular iodine for a typical synthesis (Entry l) is presented in Scheme 2.

In conclusion, we have developed a new modified. efficient and chemoselective method for the synthesis of symmetrical and unsy mmetrical SOCs catalyzed by molecular iodine with good to high yields.

\section{Expelimental}

The ${ }^{1} \mathrm{H}$ NMR ( $\left.100 \mathrm{MHz}\right)$ spectra were recorded on a Bnuker

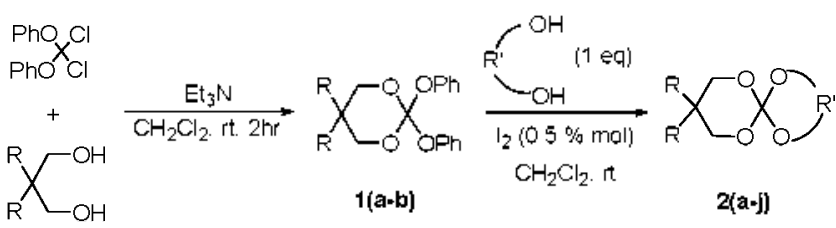

Scheme 1

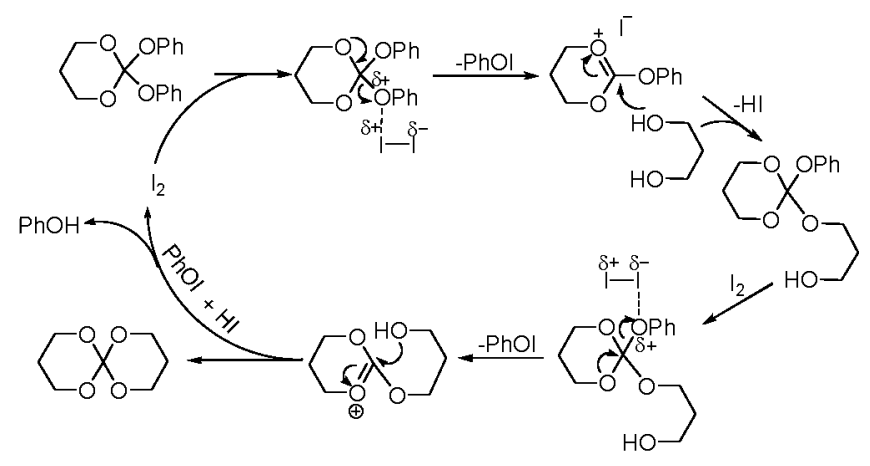

Scheme 2 
Table 2. The results of the reaction of 1,3-dioxane (1a-b) with diols in the presence of $0.5 \%$ mol molecular iodine

\begin{tabular}{|c|c|c|c|c|c|c|}
\hline \multirow{2}{*}{ Entry } & \multirow{2}{*}{ Substrate } & \multirow{2}{*}{$\begin{array}{c}\text { Time } \\
\text { (min) }\end{array}$} & \multirow{2}{*}{ Product } & \multirow{2}{*}{$\begin{array}{l}\text { Yield } \\
(\%)^{a}\end{array}$} & \multicolumn{2}{|c|}{$m p\left({ }^{\circ} \mathrm{C}\right) / \mathrm{bp}(\mathrm{mmHg})$} \\
\hline & & & & & Found & Reported \\
\hline 1 & & 30 & & 95 & $130-132$ & $133^{5}$ \\
\hline 2 & & 40 & & 90 & 113 & $112-119^{8}$ \\
\hline 3 & & 25 & & 91 & $76(2.0)$ & $68(1.0)^{+}$ \\
\hline 4 & & 40 & & 88 & $65-66$ & $67-68^{7}$ \\
\hline 5 & & 60 & & 75 & $131-133$ & $134-136^{13}$ \\
\hline 6 & & 20 & & 88 & 114 & $112-119^{8}$ \\
\hline 7 & & 30 & & 93 & $144-145$ & $143-145^{14}$ \\
\hline 8 & & 20 & & 90 & $51-53$ & - \\
\hline 9 & & 35 & & 81 & $22-24$ & $\approx 20^{\circ}$ \\
\hline 10 & & 50 & & 83 & 124 & - \\
\hline
\end{tabular}

AC 100 spectrometer. Chemical shifts are reported in ppm downfield from TMS as internal standard. The mass spectra were scanned on a Varian Mat $\mathrm{CH}-7$ at $70 \mathrm{eV}$. Elemental analysis was performed on a Thermo Finnigan Flash EA microanalyzer.

Synthesis of symmetrical and unsymmetrical SOCs $(2 \mathrm{a}-\mathrm{j})$. General procedure: To a magnetically stirred solution of synthesized corresponding 2.2-diphenoxy-1.3-dioxane (1a-b) ( $10 \mathrm{mmol}$ ) and various diols (10 mmol) in $\mathrm{CH}_{2} \mathrm{Cl}_{2}(50 \mathrm{~mL})$, molecular iodine $(0.5 \mathrm{~mol} \%$ ) was added. The progress of the reaction was monitored by TLC using petroleum ether-ethyl acetate (7:3). After the reaction was completed, the solvent was washed with $5 \% \mathrm{Na}_{2} \mathrm{~S}_{2} \mathrm{O}_{3}$ solution and water, respectively. Then the organic phase was dried over andydrous $\mathrm{Na}_{2} \mathrm{SO}_{4}$ and the solvent was removed under reduced pressure. For solid products. the precipitate was recry'stallized from ethỵl acetate. For oily liquid ones, the residue was purified by vacuum distillation. All the products were identified by comparison of their spectral and micro analytical data with those of authentic samples which was prepared according to literature. ${ }^{9}$

8,8-Dimethy]-1,4,6,10-tetraoxaspino[4.5]decane: (entry 8) ${ }^{l} \mathrm{H} \mathrm{NMR}\left(100 \mathrm{MHz} . \mathrm{CDCl}_{3}\right): \delta 0.98$ (s. $6 \mathrm{H} . \mathrm{CH}_{3}$ ). 3.90 (s. $4 \mathrm{H}$, $\left.\mathrm{CH}_{2}\right)$. 411 (s. $+\mathrm{H} . \mathrm{CH}_{2}$ ). IR $\left(v . \mathrm{cm}^{-1}\right) 2980.1190: \mathrm{mz}$ 174: Anal. Calcd. For $\mathrm{C}_{8} \mathrm{H}_{14} \mathrm{O}_{4} ; \mathrm{C} 55.16: \mathrm{H}$ 8.10: Found $\mathrm{C} 55.03: \mathrm{H}$ 8.02 .

Spim [1,3-benzodioxole-2,2'-(5,5-dimethyl)-1,3-dioxane]: (entry 10) ${ }^{l} \mathrm{H}$ NMR ( $100 \mathrm{MHz}, \mathrm{CDCl}_{3}$ ): $\delta$ i.l1 (s. 6H. $\mathrm{CH}_{3}$ ).
4.07 (s, 4H. CH ). 6.83 (m. 4H. Ph). IR (v. $\mathrm{cm}^{-1}$ ) 3122. 2993. 1205: $m z$ 222: Anal. Calcd. For $\mathrm{C}_{12} \mathrm{H}_{14} \mathrm{O}_{4}: \mathrm{C} 64.85: \mathrm{H} 6.35$; Found C 64.76: H 6.29 .

\section{References}

1. Endo, T.: Bailey, W. J. Polym Sci., Polm Chem. Ed. 1976, 1t, 1735.

2. Takata, T.; Endo, T. Prog. Polym. Sci. 1993, 18, 839

3. Rokicki, G. Prog. Polym Sci. 2000, 25, 259.

4. Sakai, S.; Kiyohara, Y.; Itoh, K.; Ishii, Y. J. Org. Chent. 1970 , 35.2347 .

5. Sakai, S.: Kobayashi, Y.: Itoh, K.; Ishii, Y.J. Org. Chem 1971, $36,1176$.

6. Endo, T.; Okawara, M. Symhesis $1984,837$.

7. Stansbury, J. W. J. Dent Res. 1992, 7I, 1408.

8. Mues, P.; Buysch, H. Sinthesis 1990, 249

9. Sanda, F.: Takata, T.: Endo, T. Macromolecules 1993, 26, 737.

10. (a) Banerjee, A. K: Vera, W: Mora, H.; Laya, M. S.; Bedoya, L.; Cabrera, E. V. J. Sci. Ind. Res. 2006, 65, 299 (b) Bakavoli, M.; Shiri, A.; Ebrahimpour, Z.; Rahimizadeh, M. Chin. Chem. Left. 2008, 19, 1403 .

11. Rahimizadeh, M.; Shir, A.; Bakavoli, M. Chin. Chem. Lett. 2007. 18,689.

12. Rahimizadeh, M.: Bakávoli, M.: Shiri, A.: Eshghi, H.: Saberi, S. J. Chent. Res. 2008, 704.

13. Sugiyama, T.; Yokozawa, T.; Endo, T. J. Polym. Sci., Part A: Polvm. Chem. 1990, 28, 3529.

14. Sakai, S: Kobayashi, Y.; Ishii, Y. J. Chem. Soc., Chen Commm. $1970,+235$. 